\title{
Improving the efficiency of conveyor transport with the use of network technologies
}

\author{
Margarita Kovalchuk ${ }^{*}$, and Dmitriy Poddubniy ${ }^{1}$ \\ ${ }^{1}$ Saint-Petersburg Mining University, Power Engineering and Electromechanic Department, 199106, 21 line, 2, Russia.
}

\begin{abstract}
Nowadays there is a tendency in the world industry to increase the number of open cast mines and the depth of work performed in them. In this regard, the problems of reliable and environmentally friendly transportation of extracted resources become especially urgent. Traditional motor vehicles is quite expensive, have problems with reliability and leads to a large gas pollution of the atmosphere, as well as the associated necessary stoppages of the open cast mine, which in turn leads to significant economic costs. The most optimal solution to these problems is the use of long conveyor lines for transportation. However, it is necessary to solve a number of problems one of them is related to the efficiency of the conveyor, which has a large length. This system needs to be controlled and monitored in real time. Thus, it is necessary to implement an automation system that meets all the specified requirements.
\end{abstract}

\section{Introduction}

The negative impact on the environment of existing types of open cast mines transport is due to the alienation of territories during the construction of transport communications, water pollution by transport and service facilities, air pollution by dust as a result of blowing it off the surface of the transported material.

In modern open cast mines, three main types of transport are used - auto, rail and conveyor transport.

Auto transport in open mines is the main source of environmental pollution. The main share of toxic impurities enters the atmosphere with the exhaust gases of the combustion engine. Auto transport, in addition, pollutes the atmosphere when driving, as a result of the interaction of automobile wheels with the road surface.

With increasing productivity and depth of the open cast mine, the environmental aspects of the operation of auto transport in the open mine become crucial. The current practice of forming open mine transport systems basically does not take into account the level of their impact on the environment, which leads to unfavorable working conditions of personnel and to significant financial losses due to downtime of open mine [1, 2].

The most environmentally friendly type of open mine transport is conveyor transport [3]. In addition, the advantage of conveyor transport in comparison with other types is the ability to fully automate the control of its work, which causes a minimum number of staff. At the same time, the operator is in a safe place with a good view, where noise and dust levels of the air are significantly reduced and the impact of machine vibrations is excluded.

To solve this problem, it is necessary to analyze the requirements for a long conveyor complex. In this paper, the requirements for the drive systems of long conveyor, the placement of equipment, sensors, control system and the choice of automation systems are considered, including the choice of industrial data transmission network.

\section{Methods}

Determining the optimal level of automation is the most difficult task. The expediency criterion of microprocessor control systems application should be the economic effect of their use. The lack of sufficiently reliable quantitative data on the costs of automation and the effect of its implementation makes it difficult to calculate the technical and economic indicators of the microprocessor control system of conveyor transport. Therefore, automation can be considered justified, if it provides increased reliability, efficiency of the mechanism, energy savings, and simplifies maintenance and repair of electromechanical equipment [4].

The most common and effective method of ensuring these requirements is the implementation of hierarchy and block-modular structure in automation systems. The independence of local automation systems from higherlevel systems improves the quality of control while reducing the degree of operator participation in the control process. The presence of a clear hierarchy in the structure of the control system allows to move from the consideration of general algorithms to a number of local ones. Electromechanical complexes of conveyor transport are characterized by five levels of hierarchy $[5,6]$ :

- the level of general control at which the operator selects the mode of operation of the complex conveyor

* Corresponding author: cheremushkina-ms@yandex.ru 
lines, the system controls the implementation of the initial conditions;

- the level of group control, which is the inclusion of service elements of conveyor transport involved in the operation of systems;

- topology selection level at which the appropriate switching equipment is controlled;

- individual control level at which the system monitors the availability of primary sources and switches on the appropriate circuit breakers;

- the executive level, at which the switches of the respective converters are switched on, the work is checked for compliance with the system operation task and, as a result, there is led indication of readiness to work, which gives permission to the operator to work.

\subsection{Control system requirements}

The implementation of the principles of modular structure and hierarchy makes it possible to standardize the element base, to increase serial production, reduce documentation and simplify system maintenance performance monitoring and troubleshooting, i.e., to improve the performance of conveyor.

At such control systems local automation equipment of individual units is expedient to replace with implementation of microprocessor system to provide interrelation between them and their control from the uniform programmable logic controller (PLC) of the top level. The use of digital control systems with controllers allows to solve qualitatively new problems of electromechanical complex (EMC) control.

In the case of a hierarchical control system, an additional requirement arises - the failure of local systems for various purposes should not lead to the failure of the entire system.

The main requirements to be met by an automated conveyor transport control system [7]:

- minimum number of preparatory operations for putting the equipment into operation;

- the flow of information to the operator must not exceed the information barrier;

- automation of maintenance operations requiring constant attention and high skills;

- failure of one of the control elements should not affect the performance of the electromechanical system as a whole.

To meet the requirements for automation of conveyor transport in general, the automation system should include:

- control subsystem that provides a set of operating modes; automatic locks that exclude emergency and irrational operating modes; control of conveyor transport operation modes according to controlled parameters;

- protection subsystem that provides measurement and processing of controlled parameters, formation and receiving of discrete signals for automatic shut-off of conveyors in emergency situations; protection against spontaneous start-up after the operation of any of the types of protection;
- the subsystem of the alarm and control providing registration and processing of parameters of electric equipment, formation and receiving of signals of the emergency and emergency-warning alarm system;

- subsystem of diagnostics of conveyors electric equipment, control and regulation systems.

The following modes are typical for control, alarm and protection subsystems:

- mode of preparation for work, in which a set of necessary operations is determined, based on the required technological or energy characteristics of the object;

- process set mode. In this case, a certain procedure must be followed, which determines the safety of work and control of the positions of the included elements;

- maintenance mode, in which the operation of the conveyor control subsystem, the control of the necessary parameters and the formation of protection signals.

In general, the requirements for the control system of a multi-conveyor line can be formulated as follows:

- multi-purpose nature of thecontrol task (providing various functions);

- multi-mode control task (providing different modes when performing each function);

- optimization of conveyor operation in each of the possible modes;

- the need for coordinated control of several conveyors, which are part of a multi-conveyor line, in order to optimize energy and functional characteristics.

\subsection{Control system structure}

The analysis of the current level of development of automation processes in various areas of production shows a high growth in the use of microelectronics and microprocessor tools, computer automation tools, the use of information technologies. This growth is due to the desire to maximize the productivity of technological equipment, the creation of fully automated production lines and robotic machines.

The process of growth of automated production is accelerated by modern achievements of microelectronics, creation of cost-effective and smallsized microprocessor tools of control and computer technology opened the way for the widespread introduction into practice of more advanced control methods with complex algorithms.

The use of programmable logic controllers (PLC), built on the basis of microprocessor technology, is the main direction of improving the automation systems of industrial complexes. These automation tools allow [8, 9]:

1. Expand functionality and improve quality indicators (speed, reliability, maintainability, level of unification, technical and economic efficiency, etc.).

2. Improve the manufacturability, simplify and reduce the cost of operation, maintenance and repair (or restoration).

3. Simplify and reduce the cost of designing automation systems. 
4. Simplify installation and dismantling, commissioning, testing of devices and systems.

5. Increase the adaptability of systems to changes in the operating conditions of the control object.

6 . Provide the most effective way to organize the dialogue mode of operation of operational personnel in automated (human-machine) control systems.

Implementation in the automatic control system (ACS) of the conveyor line digital way of information processing will significantly increase noise immunity, to ensure easy processing and transmission of information about the condition of the equipment mechanism. This allows significantly reduce the number of control equipment with electric drive, which will lead to reducing the complexity and improving the quality of maintenance and reduced time for operational troubleshooting related control equipment.

Reducing the number of control equipment will make it possible to most effectively place the equipment of the electric drive and ACS, as well as make it more convenient maintenance and increase the reliability of the entire system as a whole.

Another argument in favor of the implementation of conveyor line automation systems based on PLC is the technical quality indicators of the automation circuit elements. PLCs have power consumption less than 500 $\mathrm{W}$, the number of inclusions per hour to more than 4000 total number of shutdowns of more than 107, galvanic isolation of input and output communication with the executive device without an additional amplifier, as well as the possibility of using a single power source of the control and actuating devices.

A large number of intelligent devices and sensors in the electromechanical complex of conveyor transport requires solving the problem of local systems communication. The use of open architecture networks provides the most significant advantages of all communication methods $[10,11]$ :

- reduces the number of connecting cables and minimizes the length of analog lines;

- reduces installation cost;

- increases system flexibility and efficiency;

- provides new opportunities for diagnostics.

From the widest range of industrial tires (about 50 different tires) to allocate the best network in all respects is impossible. The most widespread are industrial networks: PROFIBUS DP / PA, CAN, INTERBUS, LON, Foundation Fieldbus, Ethernet, Modbus.

The choice of network type depends on the purpose of the network, the remoteness of the control facilities, the requirements for data transmission speed and noise immunity. Therefore, when choosing the type of industrial network in the creation of automatic control systems of electromechanical complex for multiconveyor line should be guided by international standards.

Today, one of the most common in the long conveyors applications is the CAN interface, which provides the following advantages in the communication system:

- good adaptability to control high-speed devices with increased reliability requirements;
- effective means of detecting errors at the physical level;

- exceptionally high noise immunity;

- effective use of the transmissive capacity of the line;

- ability to transmit power over the network;

- absence of auxiliary and service equipment of the network (servers, repeaters, routers, hubs, modems, bridges, etc.).

The high-speed CAN bus contains two signal lines CAN_H and CAN_L and a zero-potential GRD line (Fig. 1). The transmission of information is carried out by changing the potential difference between the signal lines. This structure allows to reduce the influence of electromagnetic interference, because physically the bus is performed as a twisted pair, and common-mode interference will not change the potential difference between the lines. To reduce the impact of interference on the transmitted data, terminator resistors are installed at the ends of the bus. The CAN bus can be in two states: dominant-corresponding to logical zero, and recessivelogical one. When the recessive and dominant state is simultaneously exposed to the bus by different nodes, the dominant level will prevail on the bus. Thus, the concept of nondestructive arbitration of the bus is realized with simultaneous exposure of packets.

Characteristics of the CAN protocol allow to assert that application of this protocol in ACS with conveyor transport will provide [11, 12]:

- high reliability of communication channel;

- built-in self-diagnosis;

- registration and recording of messages;

- ability to remotely change (upgrade) the software.

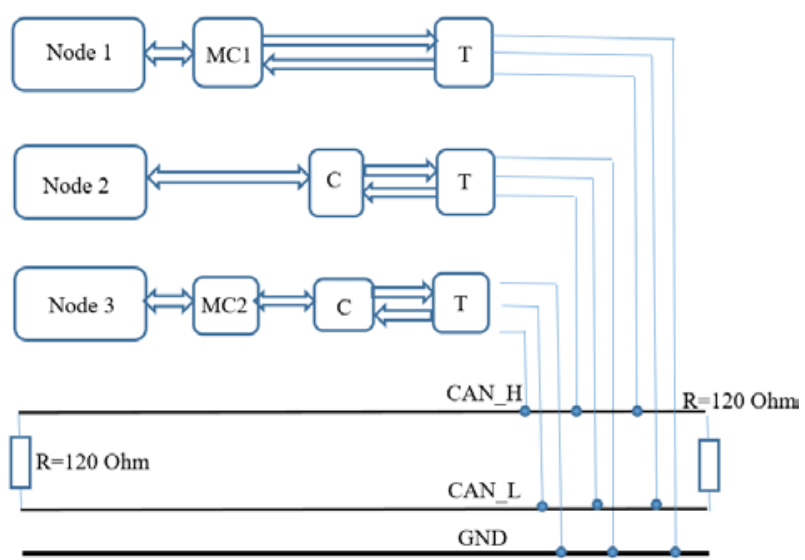

Fig. 1. Network based on the CAN interface

(MC1 - microcontroller with CAN, MC2- microcontroller without CAN, C- controllers, $\mathrm{T}$ - transceivers)

\subsection{Control system of conveyor line}

The electric drive system of the conveyor, as a rule, is multi-engine. The system generally includes two or more electric motors with electric energy converters. For example, the conveyor line considered in the work consists of four drive stations (one main station and three intermediate drive stations). Each drive station includes four drives (one master drive and three slave drives). The load balancing between drive stations is carried out with 
the use of PLC system. For the increasing reliability purposes the conveyor is equipped with tension sensors and load monitoring installations.

The flexibility and high noise immunity of the CAN communication system allows the entire composition of electrical equipment, control systems and control of conveyor equipment to be combined into a common control system. The core of the control system will be an industrial computer, which performs the following functions: information processing (loading initial information, setting the mode, report generation, data exchange with subsystems, etc.), visualization of the status and parameters of the equipment for maintenance personnel, communication with external devices (ACS of the upper stage of the hierarchy), the formation of tasks to local control systems. The role of slave devices in the industrial network will be performed by controllers of individual drive control systems, belt tension control systems, load monitoring, etc.

The electromechanical conveyor system is a nonlinear dynamic system. In order to optimize the process control of mining machines in all modes, it is necessary to use the principle of multistructural control of the electromechanical complex with implementation on microprocessor hardware. The control system of the electric drive can be referred to multi-mode systems, the behaviour of which qualitatively changes with the change of particular control objectives. Such system provides increase of work efficiency of the mining equipment, including conveyor transport, at the expense of achievement of the local purposes formulated according to process requirements of control for each mode.

The main objectives of the conveyor control system implementation are [13]:

- regulation of the conveyor speed depending on the actual load, that is, the amount of material transported;

- synchronous start and stop of several drives in order to improve performance and protect them from premature wear;

- providing remote control of the transportation process, obtaining real-time information about the process, the state of the belt, drives, control of transportation;

- diagnosis and prevention of emergency situations;

- ensuring safe operating conditions.

The analysis of the general requirements to the conveyor electric drive control system shows the need to divide the automatic control system into a control automation subsystem that performs state control operations of switching devices, formation and receiving of task signals, control of the state of drives and a subsystem that forms local algorithms for regulating the output coordinates of individual drives.

The central part of the drive control system is the controller, which programmatically changes the control mode and forms the starting and braking characteristics of the drive depending on the information received from the sensors or the drive, and the intermediate drive controllers form local control algorithms.

The electric drive of the conveyor, in general, multimotor, can be divided into two parts: the first drive is a leading one, designed to regulate the speed and form the curves of acceleration, braking and speed of the conveyor.

The output of the master drive is configured for torque and signals the input of the slave drive configured for both load limiting and torque control, which allows to evenly distribute the torque between the motors, using the necessary algorithm for adjusting the signals depending on the technological conditions (belt tension sensor) or load.

Since the masses of the relatively rigid drive complex move quickly, and their moment of inertia does not change, then at the first moment most of the starting torque developed by the engine falls on the acceleration of the drive mechanism's own masses. As the belt and the associated masses are set in motion, their share in the total accelerated mass increases, as well as the moment transmitted through the drum to the belt increases. As a result, the force in the belt increases gradually during the acceleration of the conveyor.

Therefore, the following conditions must be met to start the conveyor:

- the main drive starts and accelerates at a low speed (10\% of the rated speed) and pauses at this speed;

- intermediate drives provide the belt with a starting torque based on the information about the loading of the belt from the tension sensor, i.e. they are started taking into account the inertia of the belt;

- the moving conveyor is accelerated by switching to the acceleration curve to the working speed.

When braking, the main drive linearly slows down the conveyor until a speed equal to $5 \%$ of the rated speed is reached. At this speed, the brake is applied for the final stop of the conveyor.

Intermediate belt drive provides braking torque, based on information from the sensors of the tension of the belt. The brakes of each intermediate drive stop the conveyor when the belt speed reaches $5 \%$ of the rated speed.

For operation of the drives control system loading data of the conveyor for the purpose of a choice of minimum necessary power (moment) of electric motors are required. Therefore conveyor scales and belt tension sensors are required for the operation of the electric drive control system.

Next, consider the local control systems of individual drives, providing the task of limiting the electrical and mechanical parameters of the electric drive (rotation speed, current, voltage, torque, power, etc.) permissible values for energy and strength reasons.

Modern electric energy converters (controlled rectifiers, frequency converters, autonomous inverters, etc.) have a built-in microprocessor control system (we will call the converter's own control system and its microprocessor, on which it is built, local) [14]. Such a converter can be controlled remotely from external control devices. Local control systems have built-in optimal drive control algorithms to ensure maximum speed and accuracy of maintaining adjustable drive coordinates. Also, modern converters can provide the control system with sufficiently accurate data on the state of the electric motor: the values of voltages and 
currents, speed, torque, power consumption and temperature of the engine, which makes it possible to refuse the additional installation of many sensors. The use of local control systems for each of the drives provides the required hierarchy of the drive control system as a whole, reduces the number of operations performed by the central controller and increases the reliability of the system (modularity appears, converters can have means of self-diagnosis and diagnostics of the electric motor).

Taking into account the need to improve technical and economic indicators, as well as the increased capabilities of automatic control systems on the modern element base, it is possible to formulate the following requirements for local control systems of the electric drive of the conveyor:

- ensuring maximum performance in transient modes (start, reverse, mode change) with the restriction of adjustable coordinates in tempo and magnitude, as well as with the restriction of dynamic overloads in the belt;

- providing a range of motor speed control not lower than 1-10;

ensuring acceptable over-regulation, namely:

- the speed of the executive motor up to 20\%;

- motor current up to $100 \%$;

- the voltage at the motor up to $20-30 \%$;

- ensure static accuracy in the mode of stabilization of frequency of rotation not less than $1-2 \%$.

\section{Results}

The main direction of improvement of conveyor automation systems should be considered the development of automatic control systems based on the principles of hierarchy and modularity, having a microprocessor implementation based on programmable controllers. From a wide range of industrial networks for long conveyor lines should be used the CAN-bus. The algorithm of adjustment reference signals to the drives in multi-engine electric drive of belt conveyor allows to provide good control speed, overshoot and load distribution between drives.

\section{Discussion}

Currently, one of the main trends in the global industry is to increase energy efficiency and environmental friendliness of production.

In terms of ecological requirements, conveyor transport certainly causes the least damage to the environment. Volumes of mining and capital works on the design of transport routes are reduced to a minimum and therefore the least damage to land resources is caused. Practice has shown that conveyor transport is safer than rail and auto transport.

Energy efficiency of conveyor transport and minimization of personnel working in unhealthy conditions can be ensured through the implementation of the automation system of long conveyor lines. Thanks to the proposed system, it is possible not only to monitor and control the conveyor lines, but also to monitor the equipment in real time. This reduces the time spent on preventive maintenance of equipment and improve production efficiency in general.

In recent decades, conditions in open-pit mining have become significantly more complicated [15]. Increasing the depth of mining operations requires solving a number of technological problems, including a very important one-to ensure the operation of the transport system of the open mine. Increasing the intensity of work, the concentration of equipment, cargo traffic while increasing the depth of transportation and the associated deterioration of conditions (water, gas, increase in long slopes, etc.). Conveyors are the most promising mode of transport in terms of ensuring the delivery of rock mass from deep horizons. New technical solutions allow to create special steeply inclined conveyors that do not require a long sloping track [16]. To realize all the advantages of conveyor transport, it is necessary to solve a number of tasks for the control and automation of the transport system of the open mine. At the moment, steep-slope conveyors, allowing to work at angles up to 90 degrees and closed-type conveyor transport systems, allowing to further reduce the level of environmental pollution are considered.

\section{References}

1. G. Gao, J. Shen, Q. Liang 2018 J. Phys.: Conf. Ser. 1064, (2018)

2. D. Prostański 2018 IOP Conf. Ser.: Mater. Sci. Eng. 427 (2018)

3. R. Król, L. Gladysiewicz, D. Kaszuba, W. Kisielewski 2017 IOP Conf. Ser.: Earth Environ. Sci. 95, (2017)

4. R. Kozakov, A. Khakpour, S. Gorchekov, (...), G. Podporkin, V. Frolov, 21st Symposium on Physics of Switching Arc., FSO 2015, 5 (2015)

5. V. Frolov, A. Toropchin, Technical Physics Letters, 41(7), 3 (2015)

6. M. Baeva, J. Zalach, G. Petrov, (...), V. Frolov, D. Uhrlandt, 19th Symposium on Physics of Switching Arc, FSO 2011, 4 (2011)

7. V. Frolov, A. Kvashin, I. Murashov, ElConRus 2018, 4 (2018)

8. D. Poddubniy, E. Zagrivniy, M. Kovalchuk, ElConRus 2019, 1, 4 (2019)

9. M. Kovalchuk, S. Baburin, IOP Conference Series: Materials Science and Engineering, 7 (2018)

10. M. Cheremushkina, D. Poddubniy, IOP Conference Series: Earth and Environmental Science, 50, 7 (2017)

11. Kopteva, D. Poddubniy, V. Koptev, ElConRus 2019, 1, 5 (2019)

12. Kopteva, E. Zagrivniy, V. Malarev, ElConRus 2019, 1, 4 (2019)

13. Abramovich, P. Kuznetsov, Y. Sychev, Journal of Physics: Conference Series, 2, 5 (2018) 
14. Abramovich, Y. Sychev, P. Kuznetsov, R. Zimin, IOP Conference Series: Earth and Environmental Science, 5, 5 (2018)

15. Y. Yang, Ch. Cui, X. Guo 2019 IOP Conf. Ser.: Earth Environ. Sci. 252 (2019)

16. R. Blazej, L. Jurdziak, A. Kirjanów, T. Kozlowski 2017 IOP Conf. Ser.: Earth Environ. Sci. 95 (2017) 